\title{
NURSES AS ADVOCATES BETWEEN WESTERN AND TRADITIONAL HEALTH PRACTICES IN RSA
}

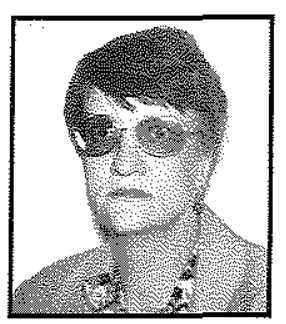

\author{
Dr. Valerie Ehlers \\ Senior lecturer, Department of Advanced Nursing Sciences \\ Registered general-, psychiatric- community health nurse, \\ midwife and nurse administrator.
}

\begin{abstract}
The RSA, like most African countries, have two health care systems. The most visible one is the Westernised hospital and/or clinic based treatment of diseases. This system was introduced by the colonisers and perpetuated by the current formal education programmes of most health care professionals in the RSA. Traditional African medicine has existed since time immemorial and continues to treat vast numbers of people. Both these health care systems will be briefly discussed. Then the role of nurses in the RSA's health care system(s) will be examined. Most professional nurses are knowledgeable about both Western and Traditional health care systems, and can thus serve as advocates between the Western health care system (frequently provided by foreigners), and the traditional healer(s) as well as to the patients/clients, together with their families. Although all health care providers need to assume responsibility for providing comprehensive health care, the professional nurses in the RSA seem to occupy the pivotal position in the health care system, to be able to co-ordinate all available health care services to the benefit of the clients and the country. However, only nurses who are knowledgeable about these prospects and who are sufficiently empowered to make and implement meaningful decisions, will be able to succeed in providing the best possible accessible and acceptable health care services to the largest number of clients - to the ultimate benefit of the entire country.
\end{abstract}

\section{OPSOMMING}

Die RSA, soos die meeste Afrika lande, het twee gesondheidstelsels. Die Westerse hospitaal en/of kliniek gebaseerde behandeling van siektes is die mees opsigtelike een, wat deur die kolonialiste daargestel is. Tradisionele Afrika medisyne bestaan sedert die vroegste tye denkbaar en behandel steeds groot getalle persone. Albei die gesondheidsorgstelsels sal kortliks bespreek word. Dan sal die rol van die verpleegkundiges in die RSA se gesondheidsorgstelsel(s) aangespreek word. Aangesien die meeste verpleegkundiges oor kennis beskik van beide die Westerse (wat dikwels deur vreemdes verskaf word), sowel as die Tradisionele gesondheidsorgstelsels, kan hulle optree as advokate tussen die Westerse en die Tradisionele gesondheidsorgstelsels asook tussen die pasiënte/kliënte en hulle families. Alhoewel alle gesondheidsorgverskaffers verantwoordelikheid moet aanvaar om 'n omvattende gesondheidsdiens daar te stel, blyk dit dat die professionele verpleegkundiges in die RSA die sleutelposisie beklee ten einde alle beskikbare gesondheidsdienste te koördineer tot voordeel van die kliënte en die land. Dit word egter beklemtoon dat slegs verpleegkundiges wat oor dié kennis beskik, en wat voldoende bemagtig is om betekenisvolle besluite te neem asook om dit uit te voer, suksesvol kan wees om die beste moontlike toeganklike en aamvaarbare gesondheidsorgdienste aan die meeste kliënte te verskaf - tot uiteindelike voordeel van die land.

\section{INTRODUCTION}

Brief discussions of both the Western and the Traditional health care systems in the RSA will precede the discussion of the role of the professional nurses as advocates between Western and Traditional health practices in the RSA. As long as two independent, often opposing, health care services exist in the country, the population of the RSA cannot receive maximum benefits from these services. Professional nurses can serve as advocates, establishing and enhancing mutual co-operation between the Western and Traditional health care sectors, in specific communities. However, professional nurses can only play this pivotal role between these two health care systems if they are knowledgeable about both systems, and if they strive to provide total health care to their clients. In order to understand the advocacy role which professional nurses could play between these two systems, some understanding of the development of both health care systems seems to be essential.

\section{HISTORICAL OVERVIEW OF THE WESTERN HEALTH CARE SYSTEMIN THE RSA}

During the colonial rule of the then Union of South Africa, the main concern of the British was to control endemic diseases, including vector-borne diseases. "Hospitals were built principally for the benefit of colonial administrators and settlers, and rural clinics were usually the by-product of missionary activities... such matters as health education, mass immunizations, screening of populations for disease, and good nutrition played only a small part in colonial policies" (World 
Bank, 1995:46). Although the RSA gained its political independence from Britain during 1960, the Apartheid regime continued providing health care more or less on the colonial guidelines until 1994. This implied that hospital care, rather than primary health care services, continued to be emphasised, until the African National Congress (ANC) proclaimed that the entire National Health Service (NHS) of the RSA should be driven by the Primary Health Care (PHC) approach (ANC, 1994b:45). The hospital-based health care approach did not recognise the contributions of traditional medicine towards providing health care, because traditional healers never operated inside hospitals, even though $80 \%$ of patients might visit traditional healers in certain communities, prior to reporting to the formal health care clinics and/or hospitals in the RSA (Gumede in Shai-Mohoko, 1996:31).

\section{The development of hospitals in the RSA}

\section{Introduction}

Hospitals have been, and in many cases continue to be, the prime providers of health care and the principal educators of health care personnel. Throughout the world, including the RSA, hospitals have been established as a result of military, religious, political or economic considerations.

\section{Military Hospitals}

The ultimate purpose of the military could be seen as organised defence (which could include killing), in sharp contrast with the healing, nurturing and caring services of nurses (Roberts \& Group, 1995:101). Yet wherever men fought wars, nurses followed to tend to the sick and wounded, often in tent hospitals and with limited equipment.

Statistics of the Crimean War illustrated the significance of providing adequate nursing care to the sick and wounded. On the other hand, statistics from the second Anglo-Boer War, fought between the British and the South African "Boer" Republics at the turn of the century, illustrated the disastrous effects which could result from absent and inadequate health services, including nursing services. A total of 27927 deaths (including 5553 children) were recorded in the concentration camps (Searle, 1970:220-224). Much illness and many deaths could have been prevented by merely isolating patients with measles, diphtheria or typhoid from all other people, by regularly cleaning the camp hospitals and by improving the diets of the people in the concentration camps.

In military hospitals, paternalism reigned, and possibly continues to reign supreme, with nurses having to accept orders not only from the doctors but also from army officers - which might not always be in the patients' best interest. Militaristic paternalism did not allow nurses, or patients, to inform military doctors about consultations with and/or treatments administered by traditional healers.

\section{Missionary Hospitals}

As more and more missionaries entered the RSA, more and more missionary hospitals were erected. Although these missionary hospitals rendered health and nursing care to the local populations, the ultimate aim might have been to convert them to Christianity through tending to their health care problems. Ministers of religion, or priests, were often the unofficial, but sometimes even the official, "overseers" of these missionary hospitals where traditional healers did not play any role whatsoever. Nurses trained by religious orders did not acknowledge the important role played by traditional health care in the lives of many African people, as the European religious workers were unfamiliar with the impact which traditional practices and healers had on the lives and well-being of many people of this country. Moreover, the religious sisterhoods trained nurses to accept the so-called female virtues of obedience to authority, hard work and little if any remuneration (Searle, 1970:152).

\section{Hospitals and Politics}

Political know-how is essential for professional survival. "No one is unaffected by politics... it is about the way people organize their lives together in a community. The important collective decisions which shape the very quality of life - our wealth, our health, our education, our mortality - are all essentially political in their nature" (Kingdom in Taylor, 1995:1182).

After the ANC (African National Congress) came to power, free health care for all mothers and children up to five years of age was announced. This was certainly a commendable political step to take, but it could have been so much more commendable - and feasible - if the health services, and especially the nurses responsible for providing most of these services, had received prior notification, improved staffing of health facilities, increased budgets and especially increased supplies of medicines. One study indicated that subsequent to these free health services, the number of consultations for minor ailments at a mobile clinic increased by $77 \%$, overextending the capabilities of the available staff (Wilkinson, Sach \& Karim, 1997:65). These "free health services" might disempower and disillusion many nurses who need to render services to many more people, without the necessary staff, facilities, equipment or drugs. Many people, who fail to obtain satisfactory health care at hospitals or clinics, might be forced to seek help from the more accessible traditional healers in the specific community.

Since politicians determine health care policies, allocate health care budgets and decide where and when health care facilities will be expanded, they influence the health care system both directly and indirectly. Unless nurses, who constitute the largest number of 
health care workers in the RSA, begin to participate in the politics of their country, they cannot begin to improve the situation for the nursing profession in the RSA, nor the health care offered to their patients/clients. Traditional healers in the RSA have requested the government to grant them statutory recognition, but this has not yet been granted. Professional nurses should be alert to such political moves in the RSA, as their future scope of professional practice might become influenced in numerous ways, should traditional healers obtain statutory recognition.

\section{Hospitals and economics}

Health care and hospitals have become big business in many developed countries, especially where prepaid medical insurance schemes virtually guarantee health care providers and hospitals to be paid for services rendered to their members. The RSA is no exception with more and more private hospitals arising in all cities and even in the larger towns of the country.

The only reason why people get admitted to hospitals is to obtain nursing care - otherwise they could get discharged from the operating tables, or receive treatment on outpatient basis (Roberts \& Group, 1995:198). Patients pay per day per bed, for medicines, bandages, minutes spent in theatre and get separate accounts from the surgeons, anaesthetist, pathologist, radiologist and physiotherapist - but no charge is levied for nursing care. Nursing care thus becomes invisible, and of no economic consequence, not only to the patients but also the hospital managers who may regard the hospitals' rates of bed occupancy and the maximum occupation of the operating theatres as generators of the hospitals' income. However, without nurses to provide nursing care, the hospital beds and the operating tables would not generate any income whatsoever. Nurses need to proclaim the absolute necessity of their services for the continued existence of all hospitals, and indeed of all health care services.

Nurses need to convince the RSA's population, politicians and economists of the necessity of nursing services for the well-being of the RSA's entire population, and of the important role nurses could play as advocates between the Western and the Traditional health care sectors to enhance the quality of health care received by the patients/clients. "Nursing is in a unique position to exercise courageous and visionary direction in proposing, initiating, and implementing interdisciplinary action toward creative community health services of a nature and amount vastly different from those that currently exist" (Rogers in Bullough \& Bullough, 1977:32).

\section{Changes in the RSA's health care system}

Soon after winning the 1994 elections, the ANC published its RDP (Reconstruction and Development Programme) report, including its health reform policies. "The aim of reorganising health services in South Africa is to improve health and health services for all. This will be done by adopting the PHC (primary health care) approach and bringing the services into line with international thinking and practices. Crucial to this will be the strengthening of community services and the development of District Health Systems" (ANC, 1994b:4). Traditional health practices, leaders and healers could play major roles in realising this ideal.

Health care providers, may function within a Westernised medical paradigm, with little or no exposure to any other culture, or any other health care system. This problem is infinitely complex in the RSA. Not only does the country have eleven official languages, and many more cultural groupings with unique health beliefs, but large numbers of the RSA's doctors, nurses and other health personnel emigrate to other countries. This vacuum is filled by recruiting health personnel, especially doctors, available from foreign countries - particularly Poland and Cuba. Doctors recruited from foreign countries are required to be able to speak English, but are not required to know anything about the vastly different cultures of the people they will treat. English could be the home language of the minority of doctors working in rural areas; the patients/clients speak eleven languages and numerous dialects; and the nurses try to be interpreters at least to the extent of getting the doctor to understand the patients' major health problems. During these interpretative sessions, nurses may play a pivotal role in helping doctors and patients to understand the complementary roles which Traditional and Western medicine could play to ensure the best possible holistic health care for individual patients.

\section{THE DEVELOPMENT OF THE TRADITIONAL HEALTH CARE SYSTEMIN THE RSA}

"Traditional medicine refers to a practice in which there is no conceptual separation between natural and supernatural entities. It entails a holistic method utilising medico-religious acts and concepts" (Setswe, 1999:57). Traditional health care, and traditional healers have been part of African societies throughout history but underwent numerous changes during colonialisation, as described by Ulin (in Ulin \& Segall, 1980:1-2): "Prior to European settlement, traditional medicine, intertwined with magic and religion, exerted powerful political influence on the conduct of public as well as private affairs. Under Protestant missionary influence and repressive political policies, colonial administrators prohibited ancient medical practices ... forcing traditional healers into a clandestine world ... In illness, the traditionally oriented individual learned to differentiate between those systems which responded rapidly to the impersonal, mechanical intervention of Western medicine and those which seemed only to yield to the more personal, culturally rooted ministrations of the traditional healer". 
This ability of patients to select either modern medical or traditional health care situations, based mainly on the perceived causes of their illnesses, enabled the traditional health care system to continue to exist and expand in the RSA. During 1999 an estimated 200000 traditional healers were practising in the RSA (Setswe, 1999:56). One of the reasons for this survival of traditional health might be its holistic approach to health, emphasising the unity of social and biological forces. "Equally important, in the past, as presently, traditional medicines have played a fundamental role in people's lives and can be used to protect, disrupt, and restore personal health and social welfare" (Waite, 1992:11). The different functions of traditional healers led to specialisation into four major groups, according to Setswe (1999:57):

- traditional doctor (or inyanga) specialising in the use of herbs, natural treatments and mixtures of animal origin; most inyangas are males who can also perform certain rituals and make preparations for luck and for fidelity

- diviner (or sangoma) who are mostly women

following a divine calling by their ancestors to define illnesses and their circumstances in cultural contexts

- faith healer (unprofiti or umthandazi), believing that healing powers come from God and/or from an ancestral spirit, they use herbs, remedies, holy water, as, laying on of hands and prayer to treat illnesses

- traditional birth attendant being an elderly woman with at least two children who underwent extensive training to assist women during pregnancy and childbirth.

The importance of functions performed by traditional healers in many communities cannot be overemphasised. "The integrative function of the traditional healer is of great importance. Through diagnosis the unknown becomes known and fear is often replaced by understanding" (Uys \& Middleton, 1997:135-136).

\section{The influence of the Primary Health Care (PHC) approach on the development of the traditional health care system in the RSA}

The focus of primary health care is the community itself. In many communities in the RSA $80 \%$ of the patients visit traditional healers before attending modern health care services (Gumede in Shai-Mahoko, 1996: 31). Less than $40 \%$ of mothers in Africa have access to trained (Western) health care personnel during childbirth (Yach, 1998:127). Consequently the health care system, and especially primary health care services in the RSA, cannot ignore traditional health care and cannot function in opposition to traditional health care services. The communities will derive the maximum health care benefit if the Traditional and Western health care sectors could collaborate because:
- Traditional healers understand local contexts and cultural codes, which give meaning to mental and physical diseases.

- Joint treatment of mentally ill patients by traditional healers and by psychiatrists has helped to update many conceptions about psychiatric illnesses.

- Traditional healers are trusted by their communities and supported in cash or in kind.

- Traditional healers can identify many disease patterns at village level as well as the indigenous herbal treatment for many diseases.

Traditional medicine does not primarily treat disease, but sick people; it does not concentrate on signs and symptoms but on the total person as a physical, psychological, social and spiritual being. This means that the entire hierarchy of forces affecting the individual - living or dead - has to be taken in account. Traditional medicine entails the " ... sum total of all knowledge and practices - whether they can be explained or not - used in the prevention, diagnosis and elimination of physical, mental or social imbalances, and relying exclusively on practical experience and observation handed down from generation to generation, whether orally or in writing" (Akerele, 1984:76).

The RSA's present government acknowledges the importance of traditional healers as part of the country's health services. "Traditional healing will become an integral and recognised part of health care in South Africa. Consumers will be allowed to choose whom to consult for their health care, and legislation will be changed to facilitate controlled use of traditional practitioners" (ANC, 1994b:55). The ANC's policy on traditional healers include the following basic principles:

- People have the right of access to traditional practitioners as part of their cultural heritage and belief system.

- The country's health service can benefit in numerous ways by co-operation between the Western and the Traditional health care providers.

- Traditional healers can help to provide health for all because they are often more accessible and more acceptable to specific groups of people than Western medicine (especially where the doctors do not understand their patients' language and/or cultures).

- Mutual education between Traditional and Western health care givers should take place so that both groups can benefit thereby.

- Traditional practitioners need to be controlled by a recognised and accepted body so that harmful practices can be eliminated and the profession promoted.

This aspect of training and control could be difficult to implement and maintain because traditional healers undergo various periods and types of training which are acceptable to each cultural group - and it should be kept 
in mind that the RSA has eleven official languages but many more cultural or ethnic groups - each with its own perceptions and traditions concerning the traditional healers.

\section{DIFFERENCES BETWEEN TRADITIONAL AND WESTERN MEDICINE}

The major differences between Traditional and Western medicine relate to their different approaches to diagnosis and treatment. Modern medicine depends on a biomedical model, which explains ailments in terms of scientifically proven pathological processes. Western medicine treats patients mostly with medicines and prescriptions, perform surgery or refer patients to psychiatrists to improve their health status. Traditional medicine views the causes of ailments to be mainly a disequilibrium within the patient's body; between the patient and the environment, family, community and/or ancestors; or disease could be caused by supernatural powers or by sorcery. Traditional treatments depend on the cause diagnosed. Rest, good food and the correct herbs can restore disequilibrium between the patient and the environment. Diseases attributed to supernatural causes are treated by prayers and by performing specific rituals (Chrisman in Patrick, 1991:46).

Besides their health functions, traditional healers play an important role in preserving social order and in reinforcing cultural practices. However, not all traditional African methods and practices are acceptable, some are detrimental to health, and some can be life threatening.

\section{NURSES AS ADVOCATES BETWEEN WESTERN AND TRADITIONAL HEALTH PRACTICES IN THE RSA}

Advocacy implies 'pleading the cause' of another person, especially if such another person is perceived to be vulnerable. "In health care the fundamental premise is that people are made vulnerable not only by the experience of illness but more significantly by the institutional processes that claim to care and cure" (Mallik, 1997:130). Nurses who understand their clients' cultures and who are knowledgeable about Western based health care processes and practices could 'plead the cause' of the clients by informing other health care team members about the clients' expectations. Simultaneously nurses could explain the need for specific treatments, operations or diagnostic procedures enabling the clients to make informed decisions.

The reality of the health care situation in the RSA encompasses medical doctors trained mostly on the Western medical model, and patients/clients who seek the help of Traditionally trained healers before, after or during their medical treatments by the Western health care system. Nurses, trained on the Western model but acquainted with the Traditional health care patterns, can link these two apparently disparate health care systems by explaining the relevant situations to the patients/clients and the doctors and/or other members of the Western health care team.

Lack of communication between medical doctors and traditional healers prevent mutual referrals that can lead to misunderstandings and accusations. Many African people seek Western medical treatment for infectious diseases but seek the help of Traditional healers when they believe the cause of their illness to be spiritual dissatisfaction or ancestral dissatisfaction with their lifestyle (Chrisman in Patrick, 1991:46). Nurses are in unique positions to discover when non-physical beliefs or fears might underlie physical signs and symptoms. In these cases nurses can save such patients much anguish and the health care system much money, if they would refer these patients to Traditional healers to get their problems sorted out. However, nurses should always encourage such patients to return to the clinic or other service should their symptoms fail to improve.

Traditional healers perform important functions in protecting people against harmful ailments - caused by sorcery through harmful agents - by placing belts or bands around the waist, neck or limbs (Chrisman in Patrick, 1991:46). Patients may arrive for surgery with such bands in place to help them safely through the surgery. Removing these bands would remove patients' protection against evil spirits and render them defenseless against evil spirits, from the patients' perspectives. Nurses might be caught between acting in the patients' best interests according to Western medicine (removing the belts and bands when preparing the patients for surgery) or according to Traditional medicine (leaving the belts and bands untouched to ensure that the patients enjoy peace of mind). Each situation should be evaluated individually and the best solution sought. Nurses who know about traditional practices often form the bridge between Western medicine - requiring sterility in operating theatres, and Traditional medicine - insisting that the patients enter the operating theatre with the bands in place. One way of resolving such a difficult issue could be by covering the belt with a sterilised bandage and by fixing it in an area outside the operating site. If the traditional healers' bands are placed around the arms or legs, which requires surgery, they can be covered with sterile bandages and positioned away from the operating site.

Some problems encountered in rendering health care to the population of the RSA, especially primary health care services, could be attributed to the adherence to Western medical approaches, proclaiming that the doctor "not only knows best", but possibly also that Western medicine is superior to Traditional health care. The medical practitioners and health care staff may lack 
exposure to any other culture, or any other health care system. Such an attitude could create tensions between what the patients (who might already have consulted traditional healers) expect and what the doctors believe the patients need (in terms of their Western medical education). Health care professionals who come from cultural backgrounds different from those of their patients, need to accept and respect the patients' cultures to achieve any success whatsoever with treatment and health education. Nurses who are familiar with the patients' cultures could play a major role in providing health care and health education acceptable to the individual patients, and benefiting their health, by both accepting and respecting cultural taboos and practices such as:

- not eating eggs while pregnant;

- preparing and eating indigenous foods, foreign to westerners, such as mopani worms;

- consulting the traditional healer prior to visiting the clinic or doctor;

- requiring the traditional healer to perform certain rituals prior to undergoing surgery; and

- accepting the importance of the forefather spirits in disease aetiology.

Nurses, coming from the same or similar cultural backgrounds as the patients/clients do understand the local contexts and cultures as well as the meaning of specific mental and physical symptoms within the cultural context. Nurses, who can explain these aspects to medical practitioners, as well as the proposed Western treatment to the patients and their families, can determine the successes or failures of the prescribed treatments by the patients and/or the families. On the other hand, successful liaison by the nurses between the traditional healers and the patients can have the same effect. For example, in cases where the traditional healers attempted treating tuberculosis sufferers before referring them to the clinic, the help of the traditional healers can be obtained to refer the patients' family members to the clinics for TB tests; to motivate the patients to take their prescribed TB treatments and to report back to the clinics for follow-up visits. In cases where the patients trust the traditional healers rather than the clinics, effective treatment can be maintained by handing the TB drugs to the Traditional healers to administer to the patient(s). Traditional healers who can effectively administer rehydration fluids, could render significant inputs towards reducing infant deaths in the RSA, because it ". . is estimated that diarrhoea is responsible for $50 \%$ of infant deaths in South Africa" (Khunoethe, 1999:29).

Especially in the field of maternal and child health care, nurses conversant with both the Western medical paradigm and the local culture, could render valuable inputs in educating not only the patients/clients but also the other members of the health care team. "Child spacing" programmes, enabling families to have as many children as they wish but also spaced as they desire, seem to be much more acceptable than programmes advocating fewer children only, where large families are culturally desirable.

Nurses, knowledgeable about Western medical treatment and Traditional health can identify cultural practices which:

- enhance health status, such as breastfeeding a baby for two years and not drinking water from a source covered with green algae;

- have no effect on health care such as placing "weaning bracelets" around the arms of toddlers in the process of being weaned; and

- definitely threaten health and possibly even life, such as rubbing cow dung into the umbilical stump of newborn babies (Byrne \& Bennett, 1986:2); or male (and female) circumcisions being performed under unhygienic conditions.

Health education efforts should not only decry those practices that threaten health but also reinforce those which enhance health. "Nurses are not only expected to be exquisite care providers, but also sensitive, knowledgeable and competent to deal with cultural factors ... culture care makes nursing relevant and meaningful" (Leininger in Mashaba \& Brink, 1994:210-211). The World Health Organisation and many health authorities show renewed interest in traditional medicines, because these offer more cost effective alternatives than manufactured pharmaceutical drugs (Mabina, Pitsoe \& Moodley, 1997:1008). On the other hand, nurses and midwives should be alert to herbal medications which might affect health outcomes. An association between maternal herbal self medication (isihlambezo meaning that which cleans) and meconium stained liquor in utero has been observed and reported at King Edward VIII Hospital in Durban (Mabina et al. 1997:1009). However, Western medicines could also be used in unscientific ways, such as administering Vitamin $\mathrm{K}$ injections many times per day to $\mathrm{TB}$ patients with haemoptysis or to bilharzia sufferers with haematuria by Portuguese trained medical officers in Mozambique (Webb in Walt \& Melamed, 1983:62).

Western medicine cannot yet cure AIDS. Consequently this is one disease which causes large numbers of people to seek traditional healers' help. Western medicine concentrates on prevention - which is useless to AIDS sufferers and probably irrelevant to people who consider themselves to be healthy. With the help of nurses, it should be possible to determine the real beliefs concerning AIDS (acquired immuno-deficiency syndrome) in each community.

Health care workers, including doctors, from foreign countries have often worked mainly with patients with light-coloured skins. For such professionals it can be problematic to diagnose a skin rash, cyanosis, anaemia or jaundice in patients with very dark-coloured skins. South African nurses could alert such foreign 
practitioners to the use of a torchlight held at right angles with the skin to distinguish a specific skin rash; diagnosing jaundice by examining the eyes, and cyanosis by checking the tongue and nails, and anaemia by checking the inside of the eyelids. However, these diagnostic signs are not as prominent in dark-skinned people as they are in light-skinned people. Therefore, diagnostic procedures need to be adapted, otherwise critical diagnostic signs might be missed with potentially lethal consequences for the patients concerned. Nurses who educate health care professionals about these differential diagnostic aspects will contribute towards the rendering of more effective health care by Western healers.

\section{CONCLUSION}

Ill health on the African continent is likely to intensify because of the escalating incidence of HIV/AIDS, malnutrition, malaria, measles and other preventable diseases. During 1990 the WHO estimated that $85 \%$ of all malaria deaths occurred in Africa, and that this figure might increase to $93 \%$ by 2020 . "In 1990 , an estimated $32 \%$ of all children who died before the fifth birthday, died in Africa. This figure is projected to increase to just under $50 \%$ by $2020 \ldots$ (implying that) in the 2020 s over 4 million deaths of children under 5 will occur annually in Africa... 220000 maternal deaths still occur annually in sub-Saharan Africa - one-third of the total" (Yach, 1998:127). One way of enhancing the health care received by Africa's people, could be to enhance the collaboration between the Western and Traditional health care sectors of African countries. Health education could play a major role in combating many of Africa's preventable diseases, but health education can only be successful if people understand and believe the health education messages.

The importance of nurses acting as advocates between the Western and the traditional health care sectors, but also between the medical practitioners and the patients, in the RSA cannot be overemphasised. The feasibility of providing health to all the RSA's citizens might hinge on this bridge which the nurses seem capable of forming between the two health sectors and between doctors, especially those from foreign countries, and many patients. Without such connections between the two health care sectors and between patients and doctors, health care in the RSA will continue to be offered in isolated sectors to the detriment of the patients, and to the disadvantage of the entire country, or even the continent. "It is these non-physicians, so closely tied to the people of Africa, who must be recognised, increasingly supported and progressively equipped to play an effective part in the delivery of proper family planning and family health care in Africa" (Marasha in Waife \& Burkhart, 1981:9). Nurses in the RSA, who succeed in enhancing the co-operation between the Western and the Traditional health care systems will succeed in enhancing the health care rendered to the people of the RSA.

I find the great thing in this world is not so much of where we stand as in what direction we are moving. Johann Wolfgang von Goethe

\section{LIST OF REFERENCES}

Akerele, O 1984: WHO's traditional medicine programme: progress and perspectives. WHO Chronicle, 38(2).

ANC 1994a: The Reconstruction and Development Programme: A Policy Framework. Pretoria: Promedia.

ANC 1994b: A National Health Plan for South Africa. Pretoria: Promedia.

Bullough, B \& Bullough, V 1977: Expanding horizons for nurses. New York: Springer.

Byrne, M \& Bennett, FJ 1986: Community nursing in developing countries: a manual for the community nurse; 2nd edition. Oxford: Oxford University Press.

Childress, JF 1982: Who should decide? Paternalism in health care. Oxford: Oxford University Press.

Feierman, S \& Janzen, JM (eds.) 1992: The social basis of health and healing in Africa. Berkeley: University of California Press.

Filio, SB. 1997: When cultures collide. Nursing and Health Care Perspectives, Sept/Oct 1997:238-243.

Khunoethe, H 1999: South African Facts. Pretoria: DENOSA.

Mabina, MH; Pitsoe, SB \& Moodley, J 1997: The effect of traditional herbal medicines on pregnancy outcome. South African Medical Journal, 87(8), 1997:10081010.

Mallik, M 1997: Advocacy in nursing - a review of the literature. Journal of Advanced Nursing, 25(1), 1997:130-138.

Mashaba, TG \& Brink, HI (eds.) 1994: Nursing education: an international perspective. Kenwyn: Juta.

Patrick, ML (ed.) 1991: Culture systems in cancer nursing: a comprehensive textbook; 2nd edition. Philadelphia: Lippincott.

Roberts, JI \& Group, TM 1995: Feminism and nursing: an historical perspective on power, status and political activism in the nursing profession. London: Praeger.

Searle, C 1970: The history of the development of nursing in South Africa 1652-1970. Pretoria: The 
South African Nursing Association.

Setswe, G 1999: The role of traditional healers and primary health care in South Africa. Health SA Gesondheid, 4(2), 1999:56-60.

Shai-Mahoko, SN 1996: Indigenous healers in the North West Province: a survey of their clinical activities in health care in the rural areas. Curationis, 19(4), 1996:31-34.

Taylor, G 1995: Politics and nursing: an elective experience. Journal of Advanced Nursing, 21, 1995:1180-1185.

Ulin, PR \& Segall MH (eds.) 1980: Traditional health care delivery in contemporary Africa. New York: Syracuse University.

Uys, L \& Middleton, L 1997: Mental health nursing. Kenwyn: Juta.

Waite, GM 1992: A history of traditional medicine and health care in pre-colonial East-Central Africa. New York: Edwin Mellen Press.

Yach, D 1998: Addressing Africa's health needs - time for strong South African involvement. South African Medical Journal, 88(2), 1998:127-129.

Waife, S \& Burkhart, C 1981: The non-physician \& the family health in Sub-Sahara Africa. USA: Pathfinder Fund.

Walt, G \& Melamed, A (eds.) 1983: Mozambique: towards a people's health service. London: Zed Books.

World Bank 1995: Development in practice: better health in Africa. Experience and lessons learned. Washington DC. 